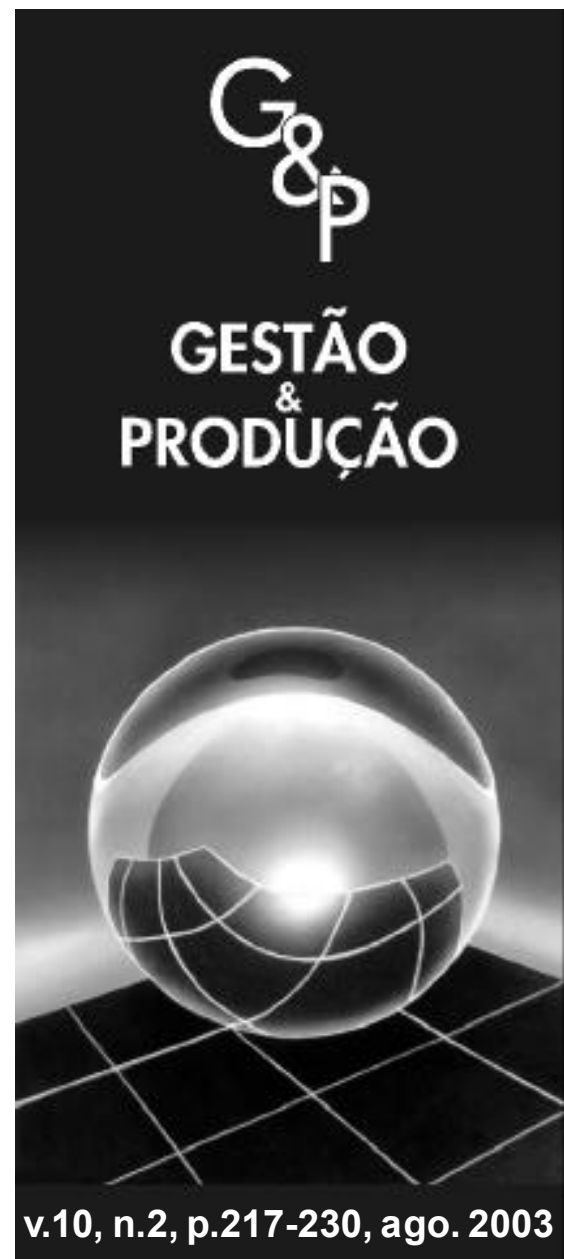

\title{
MENSURAÇÃO DA QUALIDADE DE SERVIÇOS: UM ESTUDO DE CASO NA INDÚSTRIA DE SERVIÇOS BANCÁRIOS
}

\author{
Joacir A. Machado Jr.
}

Doutor pelo Departamento de Engenharia de Produção da Escola Politécnica da Universidade de São Paulo.

Rua Correa de Lemos, 812, ap. 52, CEP 04140-000, São Paulo, SP, e-mail: joacir@unimedpaulistana.com.br

Roberto G. Rotondaro

Departamento de Engenharia de Produção da Escola Politécnica da Universidade de São Paulo, Av. Prof. Almeida Prado, 128, trav. 2, 20 andar, CEP 05509-900, Cidade Universitária, São Paulo, SP, e-mail: roberto.rotondaro@poli.usp.br

Recebido em 15/1/2002 Aceito em 27/3/2003

\section{Resumo}

A indústria de serviços experimentou notável crescimento nas últimas duas décadas. As organizações de serviços cresceram em tamanho e complexidade. Este artigo analisa a aplicação de indicadores de desempenho da qualidade na indústria de serviços bancários. O método de pesquisa adotado é o hipotético-dedutivo, aplicado por meio de um estudo de caso, em que os dados obtidos na pesquisa de campo passaram por rigorosa análise estatística para comprovação dos resultados. A organização estudada, um banco comercial, desenvolveu um modelo integrado de indicadores de desempenho da qualidade, tornando-o seu principal instrumento de gestão de qualidade. A conclusão da pesquisa revela que o desenvolvimento e a implementação de um modelo estruturado de indicadores do desempenho da qualidade contribui para o aperfeiçoamento desta, proporcionando foco para o investimento de recursos nas organizações de serviços.

Palavras-chave: gestão da qualidade, gestão de serviços, mensuração do desempenho.

\section{Introdução}

A questão inicial, que originou o tema deste artigo, tem ligação com o modelo de administração baseado na função qualidade, e de como avaliar esse modelo. Tradicionalmente as organizações dispõem de conjuntos ou sistemas de medidas de desempenho, direcionadas à avaliação do desempenho financeiro e, às vezes, da produtividade. Não obstante, o processo 
competitivo exige que as organizações busquem novas formas de produzir e também de avaliar seus resultados. Isso tem sido apontado como questão de sobrevivência.

Embora o conceito de qualidade, como um modelo gerencial, esteja em contínua atualização, será adotado neste artigo o termo gestão pela qualidade para designar a reunião das técnicas e modelos de gerenciamento pela função qualidade, em seu amplo sentido, quer seja no setor de manufatura, quer seja no de serviços. Adotou-se essa designação porque, apesar da tendência reducionista e de especialização do conhecimento, a gestão pela qualidade é assunto amplo e abrange atualmente todo tipo de organização, tanto multinacionais quanto nacionais, orientais ou ocidentais, grandes ou pequenas, de serviços ou manufatura, públicas ou privadas (DeLazaro, 1998, 1997; FNPQ, 1998).

Dentro da disciplina de gestão pela qualidade, interessa aos autores os indicadores de desempenho da qualidade. Esses indicadores são, na concepção de Takashina \& Flores (1996), formas de representar numericamente características de produtos e processos. Para Muscat \& Fleury (1993), indicadores de desempenho de qualidade são mecanismos que apontam se a organização está sendo competitiva em relação às demandas de seus clientes. Na visão desses autores, os indicadores da qualidade devem orientar a melhoria do desempenho operacional e competitivo.

Investigando a literatura acerca desse tema modelos gerenciais baseados em um conjunto integrado de indicadores de desempenho da qualidade de serviços - constata-se que a pesquisa está em fase inicial nesse campo. Nesse contexto, há explícita recomendação de pesquisas sobre o tema nos trabalhos de: Nonaka (2000), Martins (1999), Santos Neto (1999), Ramos (1998), Bandeira (1997), Urdan (1993) e Silva (1993); o que sinaliza a crescente importância do tema.

Esses autores comentam a necessidade de as organizações disporem também de um conjunto de medidas e indicadores de desempenho da qualidade, integrados aos indicadores de desempenho financeiros e da produtividade, sem, contudo, aprofundar a discussão. É essa lacuna que se pretende tratar no âmbito deste artigo.

O objetivo da mensuração é, na visão de Sink \& Tuttle (1989), Eccles (1991), Kaplan \& Norton (1996), Struebing (1996) e Mari (2000), obter conhecimento sobre o fenômeno medido. O conhecimento obtido orienta a mudança do fenômeno em direção a objetivos preestabelecidos. Então, medir o fenômeno gestão da qualidade de serviços significa obter conhecimento sobre o fenômeno e criar a possibilidade de mudança no mesmo. Este artigo é uma contribuição à questão da mensuração da qualidade dos serviços na indústria de serviços bancários e de seu significado.

\section{A questão da mensuração}

Segundo Finkelstein (1994), a mensuração e a instrumentação científicas compõem um campo de conhecimento sistematicamente organizado, que abrange a tecnologia da mensuração e da instrumentação, esse campo é a Ciência da Mensuração. Para esse autor um campo de conhecimento precisa estar sistematicamente organizado em uma teoria de conceitos e princípios genéricos, os quais orientam a ação dos praticantes do conhecimento.

Para Cropley (1998a), um objetivo imediato da Ciência da Mensuração deve ser o desenvolvimento de uma teoria que descreva o aspecto qualitativo da mensuração, pois esta tem sido abordada somente no aspecto quantitativo. A fim de desenvolver um sistema de mensuração que trate a informação de maneira excelente, o claro entendimento da natureza da informação e de como é gerada, processada e utilizada faz-se necessário, ou seja, a questão central no estudo da mensuração é o significado da informação, que expressa a relação entre o objeto representado e os símbolos utilizados para representá-lo.

A análise e a quantificação do significado da informação crescem em importância com o volume de informação colhido no processo de mensuração; assim, é difícil compreender grandes 
volumes de informação e de dados. Cropley (1998a) propõe como solução formular uma medida qualitativa da informação.

Para Cropley (1998b), a semiótica é o estudo dos sistemas simbólicos, naturais ou artificiais, e da transmissão de informação por esses símbolos. Assim, a semiótica é o método apropriado para descrever o mecanismo de transmissão de informação nos processos de mensuração.

O modelo proposto por esse autor pode ser utilizado para analisar e decodificar um processo de mensuração e a informação gerada nele. A abordagem semiótica inclui o modelo de descrição da mensuração da informação e a aplicação dos conceitos de semiótica à mensuração. A informação, nessa abordagem, tem dois aspectos: o significado simbólico, que estabelece o aspecto quantitativo da informação, e o significado qualitativo, que é orientado por três níveis da semiótica. Esses três níveis abrangem o que é intuitivamente relacionado ao significado da informação.

A relação entre as quatro fontes de significado da mensuração é determinada por meio da quantificação das formas do significado. A teoria também incorpora a compreensão dos aspectos de significado e quantitativos da informação por meio da aplicação dos conceitos da informação em outras disciplinas. A Figura 1 ilustra a teoria semiótica da mensuração da informação de Cropley (1998b).

Mari (1997) investiga a determinação e a associação na mensuração com a seguinte questão: $o$ que caracteriza a mensuração em relação a uma avaliação genérica? Esse autor observa que há uma posição tradicional, baseada na situação epistemológica da mensuração, que é: todas as coisas que podem ser acessadas por intermédio de nosso conhecimento possuem um número; pois sem os números não podemos compreender nem conhecer.

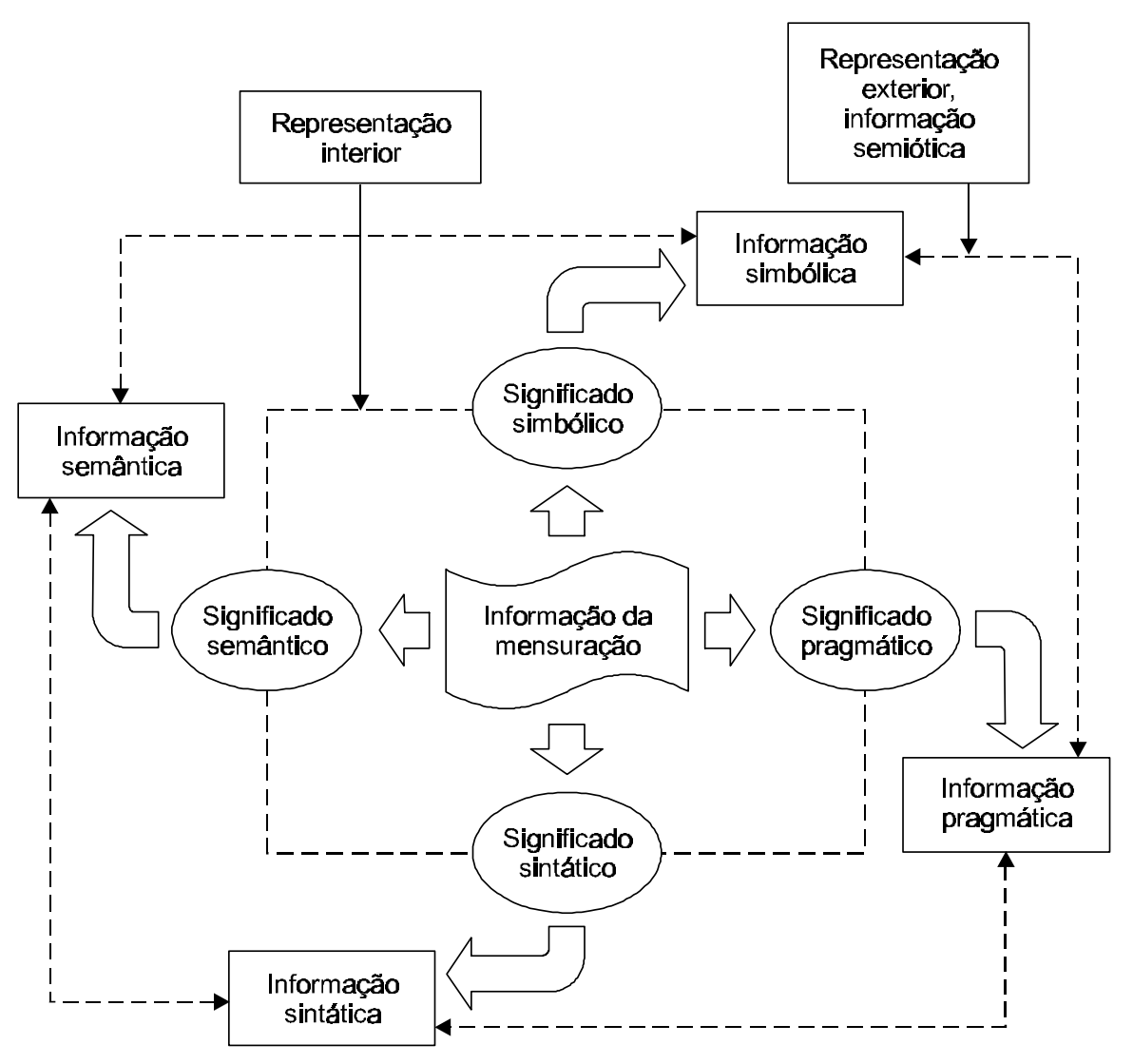

Figura 1 - Representação semiótica do processo de mensuração, segundo Cropley (1998b). 
Mari considera que o significado da mensuração tem sido fundamentado na hipótese de que os números estão na natureza e podem, então, ser apropriadamente extraídos por procedimento empírico. Desse modo, pode-se introduzir conceitos numéricos por meio da determinação de um procedimento de mensuração. Os números são associados à natureza pelas pessoas, porque os fenômenos apresentam somente as qualidades que observamos. Por isso, a visão antológica está sendo substituída por uma interpretação mais pragmática, em que a mensuração é a associação de números a objetos e eventos, de acordo com alguma regra - qualquer regra por enquanto.

Nessa nova interpretação do conceito de mensuração, Mari (1997) sugere que nada justifica a hipótese usualmente aceita - que a mensuração é uma operação empírica que produz resultados objetivos. A separação entre mensuração e avaliação simbólica genérica desaparece. Em sua proposta, Mari (1997) sugere que a regra epistemológica da mensuração seja analisada na perspectiva alternativa, entre a posição clássica e antológica e a atual, pragmática.

Para Mari (1997), as abordagens descritiva e associativa podem ser interpretadas de forma análoga: teoria da mensuração é descritiva se a exatidão do resultado é dependente do valor verdadeiro da mensuração, e é descritiva se sua exatidão está associada à satisfação de regras formais e conhecidas. Isto implica que uma sentença que expressa o resultado de uma mensuração descritiva é conhecida como tendo valor verdadeiro, às vezes desconhecido, associado a ela. Por outro lado, uma sentença contendo o resultado de uma mensuração associativa não está sujeita à condição de existência de valor verdadeiro, mas está sujeita ao reconhecimento de ser mais ou menos adequada aos objetivos da mensuração. Conseqüentemente, a sentença contendo o resultado de uma mensuração é mais verdadeira ou mais adequada.

Mari (1997) propõe, então, uma definição para mensuração como o processo empírico e objetivo de associar símbolos a objetos, em relação a atributos presentes no objeto, realizado por sistemas de mensuração que desenvolvem duas tarefas: comparação empírica da coisa com referências dadas e representação do resultado de tal comparação de forma simbólica. O objetivo de qualquer Sistema de Mensuração é associar uma entidade simbólica, assumida como resultado da mensuração, com a coisa sob mensuração, gerando assim um vínculo entre o que se chama de universo das entidades fisicas e universo dos produtos $d a$ mente humana.

\subsection{Mensuração do desempenho nas organizações}

Considerando que as abordagens gerenciais geralmente são falhas no aspecto da mensuração do desempenho, Sink \& Tuttle (1989) sugerem o sistema de mensuração do desempenho organizacional como uma função complexa, composta pela inter-relação de sete critérios: 1. eficiência; 2. eficácia; 3. qualidade; 4. produtividade; 5. qualidade de vida no trabalho; 6. inovação; e 7. rentabilidade. Se a abordagem gerencial for adequada à organização, o processo de mensuração surge naturalmente, como parte do processo gerencial.

Sink \& Tuttle (1989) argumentam que a mensuração do desempenho significa, por definição: 1. a criação de uma visão do futuro da organização; 2. o planejamento e a criação de estratégias para lograr esse futuro; 3 . o planejamento e a implementação de meios específicos para atingir objetivos de mudanças; 4. o planejamento e a implementação de um sistema de mensuração do desempenho associados a esses objetivos; e 5 . o desenvolvimento de uma cultura organizacional que apóie o sistema de mensuração.

A mensuração do desempenho da qualidade na proposta de Sink \& Tuttle (1989) deve cobrir toda a cadeia produtiva da organização. Para expressar essa visão, esses autores se valem de uma concepção sistêmica da organização, na qual identificam cinco elementos: 1 . o sistema a jusante; 2. a entrada; 3. a transformação; 4. a saída; e 5. o sistema a montante. A esses elementos os autores associam seis classes de indicadores de desempenho da qualidade, um para cada ele- 
mento da cadeia produtiva e o sexto ao próprio processo de gestão da qualidade. Cada classe contempla os seguintes aspectos:

- Indicadores da qualidade classe 1: associados ao sistema a jusante da organização, lidam com aspectos do desenvolvimento de novos produtos e serviços e seleção de fornecedores.

- Indicadores da qualidade classe 2: associados à entrada do processo produtivo da organização, apontam para os aspectos da programação e do controle da à produção e dos estoques de matérias-primas. Sua função é indicar se o processo estará ou não sob controle.

- Indicadores da qualidade classe 3: associados à transformação, ou seja, a produção em si é a forma mais clássica de controle da qualidade de processos e indicará se os requisitos da qualidade estão sendo incorporados aos produtos e serviços.

- Indicadores da qualidade classe 4: associados à saída do processo produtivo, são os processos de inspeção e verificação da produção, armazenagem e distribuição.

- Indicadores da qualidade classe 5: associados ao sistema a montante da organização, lidam com o atendimento às expectativas e necessidades do cliente, são indicadores pró-ativos que subsidiam todo o sistema a jusante.

- Indicadores da qualidade classe 6: associados a todo o sistema produtivo, monitoram a qualidade do processo gerencial da organização.

Esse modelo de Sink \& Tuttle (1989) está representado pela Figura 2 de forma esquemática. Zairi (1994) pesquisou 17 organizações, de manufatura e de serviços, vencedoras do Malcolm Baldrige National Quality Award (MBNQA) ou do European Quality Award (EQA), em busca da compreensão de seus sistemas de mensuração do desempenho no contexto de gestão de qualidade. Nessa pesquisa esse autor identificou seis grandes classes de indicadores de mensuração do desempenho: 1 . no desenvolvimento de novos produtos; 2 . a cadeia de fornecedores; 3 . em pesquisa e desenvolvimento; 4. a satisfação do cliente, 5 . em competitividade; e 6 . da cultura para a qualidade.

O argumento de Zairi (1994) é que a evolução da filosofia da gestão da qualidade leva as organizações a mudarem sua mentalidade, passando a focalizar áreas que agregam valor ao consumidor final, isto é, o autor propõe que a medida de desempenho represente o valor agregado a produtos e serviços para benefício do cliente. Segundo Zairi (1994), a adoção da gestão da qualidade proporciona benefícios financeiros de longo prazo às organizações.

Neely et al. (1995) sugerem que os modelos de mensuração de desempenho usados pelas organizações estão desatualizados, pois são baseados somente no aspecto financeiro.

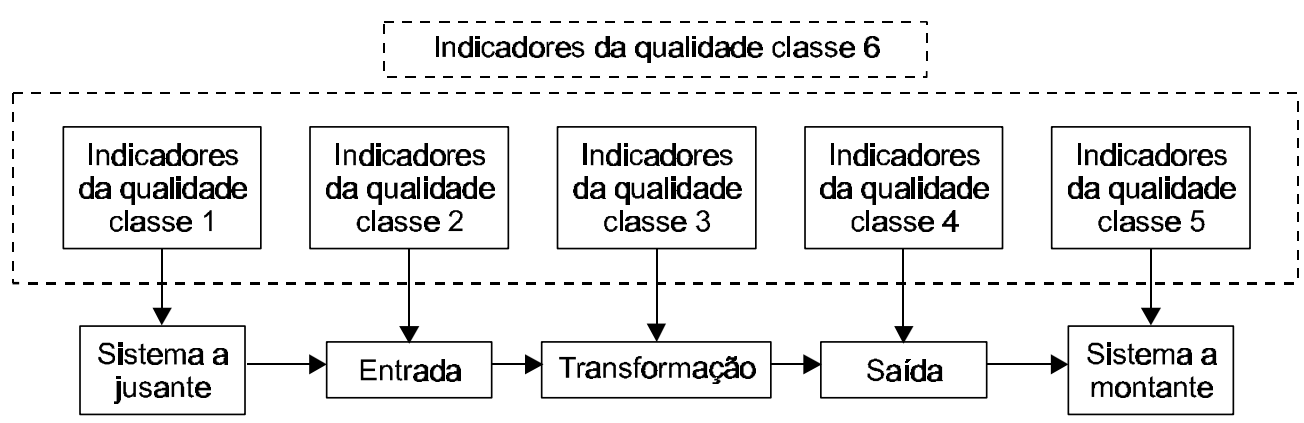

Figura 2 - Conjunto de indicadores da qualidade. Adaptado de Sink \& Tuttle (1989). 
A mensuração do desempenho é definida por esses autores como o processo de quantificar a eficácia e a eficiência de uma ação. A medida do desempenho é definida como a métrica usada para quantificar essa eficácia e eficiência. E o sistema de mensuração do desempenho é o conjunto de métricas utilizadas para quantificá-las. Para Neely et al. (1995), o sistema de mensuração do desempenho deve ser focalizado em duas dimensões: uma interna, que é a própria organização, e outra externa, que aborda o ambiente em que a organização compete.

O pressuposto básico desses autores é que o sistema de mensuração de desempenho esteja posicionado no contexto da estratégia competitiva da organização; e é relevante saber como ele influência as pessoas na realização de suas tarefas. Desse ponto de vista, os autores depreendem que as organizações, em geral, competem nos aspectos: qualidade, tempo de entrega, custo e flexibilidade.

Moreira (1996) define um sistema de mensuração do desempenho organizacional como: "o conjunto de medidas referentes à organização como um todo, às suas repartições (divisões, departamentos, seções, etc.), aos seus processos, às suas atividades organizadas em blocos bem definidos, de forma a refletir certas características do desempenho para cada nível gerencial interessado".

Para esse mesmo autor, o sistema de mensuração do desempenho é uma espécie de roteiro, em que a organização, tendo uma visão de seu futuro, traça um plano estratégico para alcançálo, guiando-se pelas metas do sistema de mensuração.

Martins \& Salerno (1998) consolidam a visão de diversos autores acerca das características que um sistema de mensuração de desempenho organizacional deve conter, considerando-se as condições competitivas que as organizações enfrentam. São elas:

1. Ser congruente com a estratégia competitiva.

2. Ter medidas financeiras e não financeiras.

3. Direcionar e suportar a melhoria contínua.
4. Identificar tendências e progressos.

5. Facilitar o entendimento das relações de causa e efeito.

6. Ser inteligível para os funcionários.

7. Abranger todo o processo, desde o fornecedor até o cliente.

8. Ter as informações disponíveis em tempo real, para toda a organização.

9. Ser dinâmico.

10. Influenciar a atitude dos funcionários.

11. Avaliar o grupo e não o indivíduo.

Martins \& Salerno (1998) consideram que, em geral, os modelos de mensuração do desempenho não apresentam abrangência suficiente para a concepção de um modelo que possibilite a integração vertical e horizontal das organizações, falta dinamismo aos modelos. Esses autores sugerem que há lacunas na literatura a serem preenchidas com pesquisas sobre os processos de implantação dos sistemas de mensuração do desempenho, da estruturação e uso das informações geradas nesses sistemas.

Neely et al. (2000) argumentam que a literatura sobre mensuração do desempenho é superficial e releva a complexidade que atualmente envolve o tema. Segundo esses autores, a questão fundamental da mensuração - como implementar o sistema - permanece sem solução. Outra questão que permanece sem resposta é: como o resultado da mensuração pode ajudar a dirigir a organização? Essas questões compõem para Neely et al. (2000) uma agenda de pesquisa.

\section{O estudo de caso}

A concepção metodológica desta pesquisa é baseada no método hipotético-dedutivo, aplicado por meio de um estudo de caso. Esse método é descrito por Lakatos \& Marconi (1986), sendo composto por quatro etapas: 1. expectativas iniciais; 2. caracterização do problema; 3. conjecturas; e 4. crítica e falseamento da solução. Esse método, segundo os autores, inicia-se pela percepção de uma lacuna 
no conhecimento, acerca da qual se formulam hipóteses e, pela inferência dedutiva, testa-se a solução proposta na hipótese da pesquisa.

O modelo de pesquisa adotado neste trabalho é o estudo de caso, tendo como referência metodológica o trabalho de Yin (1994). Esse autor reúne, em uma compilação simples, conceitos e orientações para a definição, a condução e a análise de um estudo de caso.

O objetivo desta pesquisa pode ser assim delimitado: avaliar a relevância e a pertinência de um modelo estruturado e integrado de indicadores de desempenho da qualidade, aplicado em uma organização da indústria de serviços bancários. Em outras palavras, o objetivo é constatar qual a importância do modelo de indicadores de desempenho para a gestão da qualidade dos serviços da organização e investigar sua adequação ao propósito a que se destina. Desse objetivo emergem as questões que serão analisadas no contexto desta pesquisa.

A primeira questão emergente é: a aplicação do modelo promove a melhoria da qualidade dos serviços? E a segunda é: os resultados obtidos a partir de tal modelo podem ser comprovados como relevantes sob o ponto de vista estatístico?

O objeto da pesquisa é uma organização de serviços que atua na indústria bancária de intermediação financeira, um banco comercial. A organização ocupa posição de destaque na indústria bancária nacional e detém parcela significativa do mercado bancário de varejo no segmento das pessoas físicas. Em 1992 o banco lançou um arrojado programa de mudanças internas, em cujo escopo estava prevista a criação de uma área para a gestão da qualidade no banco, além de outras ações que não estão no âmbito desta pesquisa. A área da gerência da qualidade, era responsável pelo desenvolvimento de um programa da qualidade e de sua implementação no banco. Neste escopo foi criado o modelo de indicadores de desempenho da qualidade que constitui o objeto deste estudo.
Uma das frentes da ação da gerência era a mensuração dos resultados das ações do programa da qualidade; para isso a equipe de projetos da gerência identificou os processoschave para a melhoria da qualidade. Tais processos passaram a ser monitorados pelo sistema de mensuração da qualidade. Esse sistema cresceu e em sua maturidade contava com mais de 300 indicadores de desempenho da qualidade de processos. O tamanho do sistema de mensuração da qualidade trouxe algumas dificuldades: Como analisar o conjunto de indicadores de desempenho da qualidade de processos? Como estabelecer prioridades? Quais indicadores eram, de fato, relevantes?

Tornara-se imperativo um conjunto representativo das operações fundamentais do banco e evidentemente mais enxuto. Assim, a equipe de projetos da gerência da qualidade passou a trabalhar no conceito de um único indicador que pudesse representar o conjunto de operações relevantes para o banco, que atendesse ao escopo do programa da qualidade e, principalmente, pudesse refletir, ainda que indiretamente, a percepção do cliente sobre a organização e seus serviços.

A solução encontrada pela gerência da qualidade foi a composição e o agrupamento de nove indicadores de desempenho da qualidade de processoschave, organizados em uma lógica compatível à estrutura hierárquica do banco e que representam os diversos momentos de relacionamento com os clientes ao longo da cadeia produtiva. Assim surgiu o Índice da Qualidade de Serviços (IQS). O Quadro 1 apresenta esse índice e os respectivos subíndices e indicadores de desempenho da qualidade. No quadro estão apontados, entre parênteses, os pesos que cada índice tem na composição do IQS.

A hierarquia do banco comercial é assim composta: presidente, vice-presidente do banco comercial, seis diretores regionais, 24 diretores setoriais e aproximadamente 600 agências; este último número é aproximado, pois a cada mês há abertura de novas agências, fechamento de 
agências deficitárias e fusões de agências, em um movimento que segue a dinâmica do setor.

No Quadro 1 está a representação do IQS, que é desdobrado em três níveis. Inicialmente, vê-se seu primeiro desdobramento, representado pelos índices da qualidade da agência e da qualidade de apoio. No segundo nível de desdobramento estão os índices de pesquisa, qualidade do atendimento, contas mantidas, atendimento a pedidos e disponibilidade de sistemas. Finalmente, no terceiro nível de desdobramento estão os indicadores de desempenho da qualidade: pesquisa com o cliente, pes- quisa do atendimento telefônico e porcentual de clientes que não reclamam, os quais compõem o índice de pesquisas; tempo de espera na fila (do caixa), porcentual de correspondência entregue e porcentual de dados cadastrais corretos compõem o índice da qualidade de atendimento. Por fim, os indicadores: porcentual de contas mantidas, atendimento a pedidos na retaguarda e disponibilidade de sistemas eletrônicos confundem-se com seus índices. Os indicadores do terceiro nível são apurados mensalmente e consolidados por operações aritméticas.

\section{Quadro 1 - Índice da qualidade de serviços e seus desdobramentos em índices e indicadores do desempenho da qualidade. Elaborado pelos autores.}

\begin{tabular}{|c|c|c|c|}
\hline $\begin{array}{c}3^{\circ} \text { nível de } \\
\text { desdobramento }\end{array}$ & $\begin{array}{c}2^{2} \text { nível de } \\
\text { desdobramento }\end{array}$ & $\begin{array}{c}1^{\circ} \text { nível de } \\
\text { desdobramento }\end{array}$ & $\begin{array}{l}\text { Índice da qualidade } \\
\text { de serviços (IQS) }\end{array}$ \\
\hline $\begin{array}{c}\text { Indicadores de } \\
\text { processos-chave no } \\
\text { âmbito de áreas } \\
\text { operacionais e agência }\end{array}$ & $\begin{array}{l}\text { Índices no âmbito das } \\
\text { gerências }\end{array}$ & $\begin{array}{c}\text { Índices no âmbito das } \\
\text { diretorias }\end{array}$ & $\begin{array}{l}\text { Índice no âmbito da } \\
\text { vice-presidência }\end{array}$ \\
\hline $\begin{array}{l}\text { Pesquisa com o } \\
\text { cliente }\end{array}$ & \multirow{3}{*}{$\begin{array}{l}\text { Índice de pesquisas } \\
\quad(\text { peso }-25 \%)\end{array}$} & \multirow{7}{*}{$\begin{array}{c}\text { Índice da } \\
\text { qualidade da agência } \\
\text { (peso-80\%) }\end{array}$} & \multirow{9}{*}{$\begin{array}{c}\text { Índice da qualidade } \mathrm{d} \\
\text { serviços }\end{array}$} \\
\hline $\begin{array}{l}\text { Pesquisa do } \\
\text { atendimento } \\
\text { telefônico }\end{array}$ & & & \\
\hline $\begin{array}{l}\text { Porcentual de } \\
\text { clientes que } \\
\text { não reclamam }\end{array}$ & & & \\
\hline $\begin{array}{c}\text { Tempo de espera } \\
\text { na fila do caixa }\end{array}$ & \multirow{3}{*}{$\begin{array}{l}\text { Índice da qualidade do } \\
\text { atendimento } \\
\text { (peso }-25 \%)\end{array}$} & & \\
\hline $\begin{array}{l}\text { Porcentual de } \\
\text { correspondência } \\
\quad \text { entregue }\end{array}$ & & & \\
\hline $\begin{array}{l}\text { Porcentual de } \\
\text { dados cadastrais } \\
\text { corretos }\end{array}$ & & & \\
\hline $\begin{array}{l}\text { Porcentual de } \\
\text { contas mantidas }\end{array}$ & $\begin{array}{c}\text { Índice de contas mantidas } \\
\text { (peso }-50 \% \text { ) }\end{array}$ & & \\
\hline $\begin{array}{l}\text { Atendimento a } \\
\text { pedidos de } \\
\text { retaguarda }\end{array}$ & $\begin{array}{c}\text { Índice de atendimento a } \\
\text { pedidos } \\
(\text { peso }-40 \%)\end{array}$ & \multirow{2}{*}{$\begin{array}{c}\text { Índice da } \\
\text { qualidade do apoio } \\
\text { (peso }-20 \%)\end{array}$} & \\
\hline $\begin{array}{l}\text { Disponibilidade } \\
\text { de sistemas } \\
\text { eletrônicos }\end{array}$ & $\begin{array}{l}\text { Índice da disponibilidade } \\
\text { de sistemas } \\
\text { (peso-60\%) }\end{array}$ & & \\
\hline
\end{tabular}




\subsection{Uso do IQS como instrumento gerencial}

A vice-presidência, responsável pela gestão da rede de agências do banco, adota o IQS como instrumento de avaliação do desempenho em qualidade das agências. Essa avaliação ocorre no âmbito dos comitês da qualidade das agências, comitês da qualidade das diretorias e comitê da qualidade da vice-presidência do segmento banco comercial. Esses comitês articulam-se hierarquicamente, de tal forma que as decisões tomadas no comitê da vice-presidência desdobram-se em ações nos comitês das diretorias. Que, por sua vez, determinam ações no âmbito da rede de agências e departamentos. Os resultados dessas ações são avaliados pelos índices que compõem o IQS, cada um avaliado em seu respectivo nível organizacional. Os ciclos são semestrais para a vice-presidência e mensais para os demais.

Em junho de 1996 a vice-presidência do banco comercial estabeleceu o Plano Anual de Acompanhamento da Qualidade, valendo-se dos níveis dos comitês da qualidade, em que foram propostas ações nos diversos níveis organizacionais. Desse modo, os processos reproduzidos no IQS passaram a receber ações específicas de melhorias; nessa atividade, a organização utilizou os instrumentos de gestão pela qualidade, o treinamento e os grupos de melhoria, por meio da criação de Círculos de Controle da Qualidade (CCQ).

O Plano Anual considerou prioritárias as seguintes ações: a) o esforço pela manutenção de clientes na carteira, com resultados evidentes no índice de contas mantidas; b) o esforço para atualização da base de dados cadastrais de clientes, com resultados no índice da qualidade do atendimento; e c) treinamento no atendimento telefônico para os colaboradores que trabalham nas agências, com resultado positivo no índice de pesquisas.

Para o índice da qualidade do apoio, subordinado à diretoria administrativa, não foram encontradas evidências de ações específicas para melhoria nos índices desse âmbito. O Gráfico 1 exibe o IQS para o nível da vice-presidência e o Gráfico 2 representa os índices da qualidade da agência e da qualidade do apoio para o mesmo nível hierárquico.

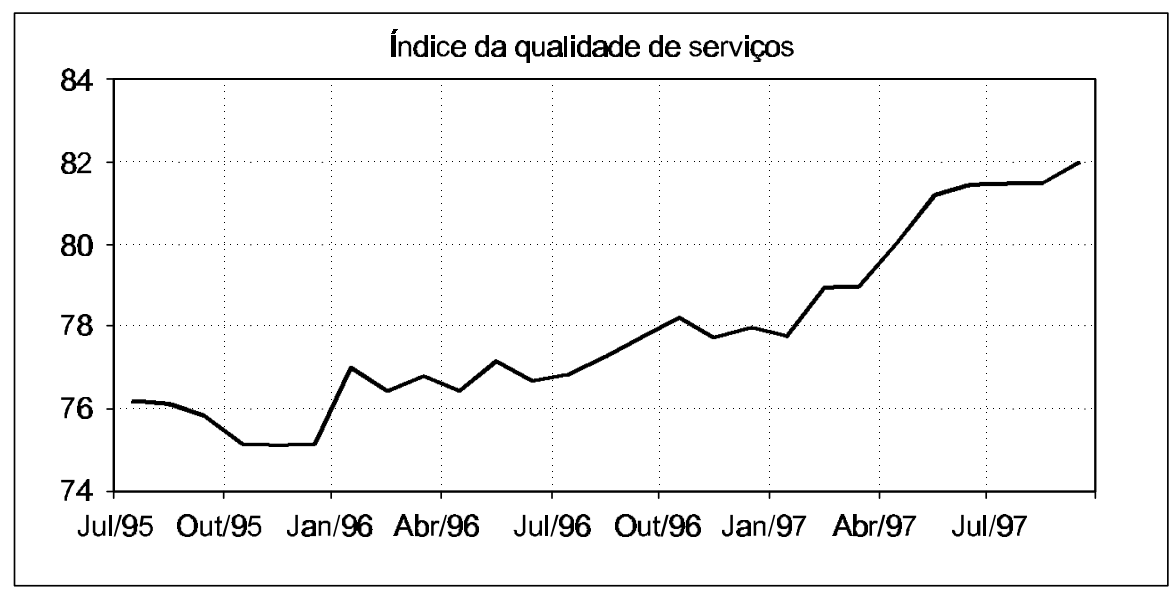

Gráfico 1 - Reprodução do índice da qualidade de serviços para o nível de vicepresidente. Elaborado pelos autores. 

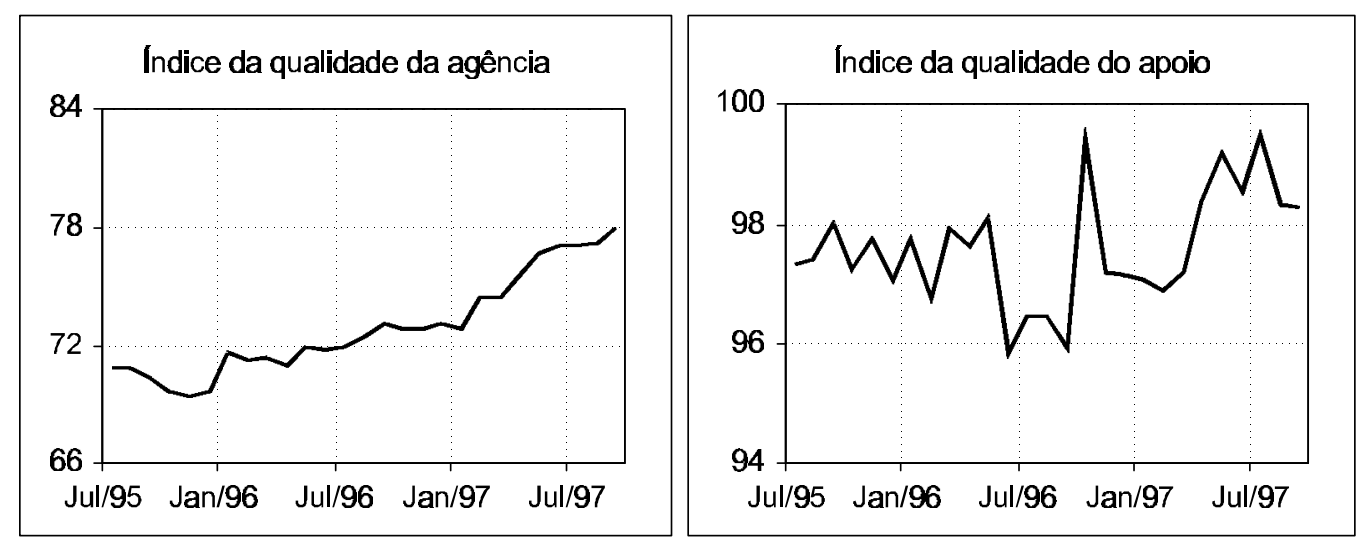

Gráfico 2 - Reprodução dos índices da qualidade da agência e da qualidade do apoio. Elaborado pelos autores.

\subsection{Resultados}

Os dados do IQS obtidos na pesquisa de campo foram submetidos à análise estatística com o objetivo de encontrar evidências de que os estilos gerenciais, impostos pelos diretores às suas agências, são diferentes; além disso, foi investigado se tais estilos modificam o comportamento dos indicadores de desempenho e do IQS. A suposição inicial é de que os estilos gerenciais não afetam o desempenho do IQS e de seus indicadores, sendo seus resultados puramente casuais e não dependentes da ação gerencial dos diretores.

Para investigar esses fenômenos foram testadas as seguintes hipóteses: a) os estilos gerenciais dos diretores de níveis regional e setorial afetam o desempenho da região e do setor comercial em relação ao IQS; e b) o tempo (medido em meses) afeta o desempenho do IQS. Para testar essa última hipótese, a variável tempo foi dividida em três blocos de nove meses consecutivos cada. Os testes de hipóteses estão baseados na abordagem de Hocking (1996) para análise estatística multivariada.

Para aplicar esses testes de hipóteses, os autores valeram-se do programa de computador para análise estatística Statistical Analysis Sistem (SAS). Os resultados dos testes das hipóteses a e b são apresentados na Tabela 1. Para visualizar as diferenças de desempenho do IQS em relação às diretorias regionais e ao tempo, aplicou-se o teste de comparação de médias de Ryan, Einot, Gabriel e Welsch, calculado pelo programa $S A S$, apresentado nas Tabelas 2 e 3. Esse teste ordena e agrupa as médias consideradas iguais, do ponto de vista estatístico, sob o nível de confiança de $95 \%$.

\section{Conclusão e discussão}

Considerações sobre a primeira questão: o Plano Anual de Acompanhamento da Qualidade, estabelecido pela vice-presidência do banco comercial, centralizou no IQS a avaliação do desempenho em qualidade, possibilitando a implementação de melhorias concretas nos processos-chave representados pelo IQS. Nesse sentido, a análise da variável tempo, na Tabela 2 , revelou-se importante para a comprovação da melhoria do desempenho do IQS. Nos nove primeiros meses de uso do IQS, sua média foi de 75,9 pontos; nos nove meses seguintes, foi de 77,4 pontos; e nos últimos nove meses pesquisados, de 80,4 pontos. Essas médias são diferentes entre si, o que equivale dizer que a qualidade melhorou nesses períodos. 
Tabela 1 - Tabela de análise de variância do índice da qualidade de serviços. Elaborada pelos autores.

\begin{tabular}{lccccc}
\hline $\begin{array}{l}\text { Fonte de } \\
\text { variação }\end{array}$ & $\begin{array}{c}\text { Graus de } \\
\text { liberdade }\end{array}$ & $\begin{array}{c}\text { Soma de } \\
\text { quadrados }\end{array}$ & $\begin{array}{c}\text { Quadrados } \\
\text { médios }\end{array}$ & F crítico & $\begin{array}{c}\text { Probabilidade do } \\
\text { F crítico }\end{array}$ \\
\hline Modelo & 68 & $4.518,9$ & 66,4 & 26,4 & 0,0001 \\
Região (A) & 5 & 915,5 & 183,1 & 72,6 & 0,0001 \\
Setor (A) & 18 & 810,3 & 45,0 & 17,9 & 0,0001 \\
Tempo (B) & 2 & 2093,6 & $1.046,8$ & 415,0 & 0,0001 \\
Int. Reg/Tem & 10 & 339,2 & 33,9 & 13,5 & 0,0001 \\
Int. Set/Tem & 33 & 360,3 & 10,9 & 4,3 & 0,0001 \\
Erro & 546 & $1.377,2$ & 2,5 & & \\
Total & 614 & $5.896,1$ & & &
\end{tabular}

Tabela 2 - Teste comparativo de médias de Ryan, Einot, Gabriel e Welsch do IQS em relação à variável tempo. Elaborado pelos autores.

\begin{tabular}{lccc}
\hline Tempo & Média & Agrupamento & N (quantidade de pontos) \\
Julho/95 a março/96 & 75,9 & $\mathrm{~A}$ & 216 \\
Abril/96 a dezembro/96 & 77,4 & $\mathrm{~B}$ & 210 \\
Janeiro/97 a setembro/97 & 80,4 & $\mathrm{C}$ & 189 \\
\hline
\end{tabular}

Tabela 3 - Teste comparativo de médias de Ryan, Einot, Gabriel e Welsch do IQS em relação às diretorias regionais. Elaborado pelos autores.

\begin{tabular}{lccc}
\hline Região & Média & Agrupamento & N (quantidade de pontos) \\
\hline Região 6 & 74,9 & $\mathrm{~A}$ & 97 \\
Região 4 & 72,3 & $\mathrm{~B}$ & 108 \\
Região 3 & 71,7 & $\mathrm{~B}$ & 97 \\
Região 1 & 69,1 & $\mathrm{C}$ & 81 \\
Região 5 & 68,4 & $\mathrm{C}$ & 81 \\
Região 2 & 67,9 & $\mathrm{C}$ & 151 \\
\hline
\end{tabular}


A análise da Tabela 1 permite inferir que há diferenças de desempenho do IQS em relação à estrutura hierárquica. A natureza das ações de melhoria da qualidade é diferente entre as diretorias regionais e também entre as diretorias setoriais. Essas ações são diferentes em intensidade e poder de mudança, em outras palavras, o desempenho do IQS muda, segundo as diretorias. A Tabela 3 informa quais as regiões com melhor desempenho do IQS. A região 6 obteve melhor desempenho do IQS com média de 74,9 pontos. Em seguida estão as regiões 4 e 3, com médias iguais do ponto de vista estatístico, e, por último, as regiões 1, 5 e 2 que apresentam o mesmo desempenho do IQS, esses resultados indicam que os estilos gerenciais dos diretores são diferentes entre si.

A segunda questão pode ser assim encaminhada: os resultados de melhoria do IQS são significativos do ponto de vista estatístico, comprovados pelas Tabelas 1,2 e 3 . As hipóteses a e b são aceitas como verdadeiras, com mais de $99,90 \%$ de confiança (na coluna probabilidade do F crítico, Tabela 1) e os testes de médias, nas Tabelas 2 e 3 , estão padronizados a $95 \%$ de confiança.

Se for adotada a abordagem de Cropley (1998a, 1998b) para interpretar o IQS, pode-se considerar que esse modelo é uma sintaxe, isto é, uma forma de ler e reescrever a organização; o modelo possui uma semântica, que é o discurso gerado pela recriação da organização; e seu pragmatismo é a melhoria da qualidade, envolto em um simbolismo, a cultura da excelência. A semântica e a sintaxe dizem respeito à forma da mensuração do desempenho e o pragmatismo e o simbolismo referemse ao conteúdo e ao significado dessa mensuração.

Se adotada a abordagem de Mari (1996, 1997, 2000) para analisar o IQS, constata-se que ele é uma representação simbólica, concretizada por meio da representação de um universo empírico, o do fenômeno da gestão pela qualidade. Essa representação se dá por meio de uma medida associativa, que não tem valor verdadeiro (ou esperado), mas é considerada adequada a seu propósito; desse modo, o IQS é auto-referente. Acima de tudo, são representações da ação humana.

O IQS apresenta estrutura semelhante à proposta por Sink \& Tutlle (1989), por meio da abordagem sistêmica da operação da organização. A divisão do IQS em subíndices procura reproduzir o caminho da realização dos serviços entregues aos clientes, serviços cujos níveis de desdobramento representam as instâncias decisórias da organização. A concepção do IQS levou em consideração processos que agregam valor aos serviços oferecidos aos clientes, como a gestão do tempo de espera na fila, na direção da proposta de Zairi (1994) para a mensuração de desempenho da qualidade.

O IQS pretende reproduzir toda a operação da organização que represente valor agregado ao cliente. Ele pretende, portanto, ser abrangente, integrando os níveis gerenciais e as unidades operacionais da organização. Isto aponta para potenciais soluções ao problema identificado por Martins \& Salerno (1998) - a falta de abrangência dos sistemas de mensuração do desempenho das organizações que possibilitem a integração horizontal e vertical das organizações. No entanto, a solução desse problema não é simples; parece pouco provável que modelos predefinidos, oriundos de algum receituário, apresentem soluções suficientemente abrangentes para qualquer organização. Talvez soluções personalizadas, para cada organização, apresentem melhores resultados.

Lidar com indicadores de desempenho da qualidade traz o problema de quais e quantos indicadores são necessários para gestão e melhoria da qualidade eficientes. A experiência vivida pela organização, objeto desta pesquisa, ajuda na compreensão dessas questões. Inicialmente, a organização dispunha de grande número de indicadores, mais de 300, com finalidades e objetivos não necessariamente congruentes. Reduzir o conjunto de indicadores, procurando aqueles com maior poder representativo das operações, foi uma solução que proporcionou foco nas ações de melhorias e no investimento dos recursos. É razoável supor que 
o IQS evoluirá, adaptando-se às novas realidades da organização.

Esta pesquisa tratou da análise de um conjunto integrado de indicadores de desempenho da qualidade em serviços, adotado por uma organização da indústria de serviços, um banco comercial. Nessa organização, o conjunto de indicadores, o IQS, serviu ao propósito de orientar melhorias da qualidade em atividades importantes para o relacionamento entre o banco e seus clientes.
Essa experiência pode ser estendida a outras organizações que operem serviços padronizados e com grandes redes de distribuição, como bancos, escolas públicas ou privadas, saúde pública ou privada, telecomunicações, fornecimento de energia, transporte público, dentre outros, os quais poderiam se beneficiar sobremaneira de um modelo semelhante ao IQS, proporcionando foco no investimento de recursos e na identificação de problemas localizados.

\section{Referências Bibliográficas}

BANDEIRA, A. A. Rede de indicadores de desempenho para gestão de uma usina hidroelétrica. 1997. Dissertação (Mestrado) Escola Politécnica, Universidade de São Paulo, São Paulo.

CROPLEY, D. H. Towards formulating a semiotic theory of measurement information - Part 1. Measurement, v. 24, p. 237-248, 1998a.

Towards formulating a semiotic theory of measurement information - Part 2. Measurement, v. 24, p. 249-262, 1998 b.

DELAZARO FILHO, J. Gestão de qualidade no Brasil, setor de serviços. São Paulo: Núcleo de Pesquisas e Publicações, Fundação Getúlio Vargas, 1998.

Gestão de qualidade no Brasil, setor de manufatura. São Paulo: Núcleo de Pesquisas e Publicações, Fundação Getúlio Vargas, 1997.

ECCLES, R. G. The performance measurement manifesto. Harvard Business Review, v. 69, n. 1, p. 63-74, 1991.

FINKELSTEIN, L. Measurement and instrumentation science - An analytical review. Measurement, v. 14, p. 3-14, 1994.

FUNDAÇÃO PARA O PRÊMIO NACIONAL DA QUALIDADE (FNPQ). Critérios da excelência: o estado da arte da gestão para a excelência do desempenho. São Paulo: Fundação Nacional para a Qualidade, 1998.
HOCKING, R. R. Methods and applications of linear models. New York: John Wiley \& Sons, 1996.

KAPLAN, R. S.; NORTON, D. P. The balanced scorecard. Boston: Harvard Business School Press, 1996.

LAKATOS, E. M.; MARCONI, M. de A. Metodologia científica. São Paulo: Atlas, 1986.

MARI, L. Beyond the representational viewpoint: a new formalization of measurement. Measurement, v. 27, n. 3, p. 79-90, 2000.

The role of determination and assignment in measurement. Measurement, v. 21, n. 3, p. 7990, 1997.

. The meaning of "quantity" in measurement. Measurement, v. 17, n. 2, p. 127-138, 1996.

MARTINS, R. A.; SALERNO, M. S. Sistema de medição de desempenho: uma revisão da literatura. Boletim Técnico da Escola Politécnica. Universidade de São Paulo, BT/PRO/063, São Paulo, 1998.

MARTINS, R. A. Sistemas de medição do desempenho: um modelo para estruturação do uso. 1999. Tese (Doutorado) - Escola Politécnica, Universidade de São Paulo, São Paulo.

MOREIRA, D. A. Dimensões do desempenho em manufatura e serviços. São Paulo, Pioneira, 1996.

MUSCAT, A. R. N.; FLEURY, A. C. C. Indicadores da qualidade e produtividade na indústria brasileira. Revista Indicadores da Qualidade e Produtividade, Brasília, v. 1, n. 1, p. 57-78, 1993. 
NEELY, A.; GREGORY, M.; PLATTS, K. Performance measurement system design: a literature review and research agenda. International Journal of Operations \& Production Management, v. 15, n. 4, p. 80-116, 1995.

NEELY, A.; MILLS, J.; PLATTS, K.; RICHARDS, H.; GREGORY, M.; BOURNE, M.; KENNERLEY, M. Performance measurement system design: developing and testing a process-based approach. International Journal of Operations \& Production Management, v. 20, n. 10, p. 119-145, 2000.

NONAKA, P. K. As contribuições da teoria da qualidade ao marketing de relacionamento: um estudo de caso na indústria bancária. 2000. Dissertação (Mestrado) - Faculdade de Economia, Administração e Contabilidade, Universidade de São Paulo, São Paulo.

RAMOS, D. Práticas para a excelência na gestão de serviços: um estudo exploratório no setor na cidade de São Paulo. 1998. Dissertação (Mestrado) - Faculdade de Economia, Administração e Contabilidade, Universidade de São Paulo, São Paulo.

SANTOS NETO, J. P. dos. Estratégia e vantagem competitiva na prestação de serviços: uma abordagem para a administração de serviços de assistência médica. 1999. Dissertação (Mestrado) Faculdade de Economia, Administração e Contabilidade, Universidade de São Paulo, São Paulo.
SILVA, P. R. da. Mensuração do desempenho estratégico e operacional na excelência de manufatura de classe mundial. 1993. Tese (Doutorado) - Faculdade de Economia, Administração e Contabilidade, Universidade de São Paulo, São Paulo.

SINK, D. S.; TUTTLE, T. C. Planning and measurement in your organization. Norcross, Industrial engineering and management Press, 1989.

STRUEBING, L. Measuring for excellence. Quality Progress, v. 29, n. 12, p. 25-28, 1996.

TAKASHINA, N. T.; FLORES, M. C. X. Indicadores da qualidade e do desempenho. Rio de Janeiro: Qualitymark, 1996.

URDAN, A. T. Qualidade de serviços: proposição de um modelo integrativo. 1993. Tese (Doutorado) - Faculdade de Economia, Administração e Contabilidade, Universidade de São Paulo, São Paulo.

YIN, R. K. Case study: research, design and methods. Thousand Oaks: Sage, 1994.

ZAIRI, M. Measuring performance for business result. London: Chapman \& Hall, 1994.

\title{
MEASUREMENT OF SERVICE QUALITY: A CASE STUDY IN THE INDUSTRY OF BANKING SERVICES
}

\begin{abstract}
The service industry tried notable growth in the last two decades. The service organizations had grown in size and complexity. This work analyzes the application of performance indicators of quality in the industry of banking services. The adopted method of research is the hypothetical-deductive one, applied through a case study, where the data gotten in the field research had passed for rigorous statistical analysis, for corroborate of the results. The studied organization, a commercial bank, developed an integrated model of performance indicators of quality, becoming its main instrument of management of the quality. The conclusion of the research discloses, that the development and implementation of a structured model of performance indicators of quality, contribute for the improvement of quality, providing focus for the investment of resources in the service organizations.
\end{abstract}

Key words: quality management, service management, performance measurement. 